\title{
JUSTIÇA RESTAURATIVA, CRIMINOLOGIA CRÍTICA E COOPTAÇÃO LIBERAL: POSSÍVEIS CONTRIBUTOS DA TEORIA MARXISTA A UMA JUSTIÇA RESTAURATIVA CRÍTICA
}

\section{RESTORATIVE JUSTICE, CRITICAL CRIMINOLOGY AND LIBERAL CO-OPTATION: POSSIBLE CONTRIBUTIONS OF MARXIST THEORY TO A CRITICAL RESTORATIVE JUSTICE}

\author{
Lucas Romero Leite* \\ Paloma Machado Graf**
}

\section{Resumo}

O movimento restaurativo ganhou destaque na contemporaneidade ao ampliar as áreas de aplicação, mas sem desenvolver uma perspectiva crítica contra o paradigma punitivista e o discurso jurídico liberal em geral. Desta forma, para além da ostensiva neoconservadora, o risco de cooptação liberal da justiça restaurativa é agravado pela fluidez teórica e pela falta de unicidade finalística entre as vertentes restaurativas existentes. Neste panorama, a teoria marxista oferece relevantes contribuições para a consolidação de uma justiça restaurativa crítica, contraposta ao punitivismo e ao discurso jurídico penal liberal, que enfrenta a hegemonia opressora das instituições ao se apresentar como instrumento de empoderamento e responsabilização. Assim, para dar conta desta construção crítica, o presente artigo, por meio de uma análise bibliográfica e abordagem dialética, tem como objetivo identificar os possíveis contributos da teoria marxista ao desenvolvimento de uma justiça restaurativa crítica.

Palavras-chave: Justiça restaurativa crítica. Criminologia crítica. Criminologia marxista.

\section{Abstract}

The restorative movement has gained prominence in contemporaneity by expanding areas of application, but without developing a critical perspective against the punitivist paradigm and liberal legal discourse in general. Thus, beyond the ostensible neoconservative, the risk of liberal co-optation of restorative justice is aggravated by theoretical fluidity and the lack of finalistic uniqueness among existing restorative strands. In this panorama, Marxist theory offers relevant contributions for the consolidation of a critical restorative justice, opposed to punitivism and the liberal penal legal discourse, which confronts the oppressive hegemony of institutions by presenting itself as an instrument of empowerment and accountability. Thus, to account for this critical construction, the present article, through a bibliographical analysis and dialectical approach, aims to identify the possible contributions of Marxist theory to the development of a critical restorative justice.

Keywords: Critical restorative justice. Critical criminology. Marxist criminology.

\footnotetext{
"Mestranda em Educação, Cultura e Comunicação em Periferias Urbanas (FEBF/UERJ). Professora de filosofia e sociologia do Ensino Médio na Rede Pública do Estado do Rio de Janeiro-SEEDUC. Integrante do Grupo de Pesquisa Educação e Cibercultura - EduCiber. E-mail: anacfeijole@gmail.com.

"Doutoranda em Ciências Sociais Aplicadas pela Universidade Estadual de Ponta Grossa (UEPG), mestra pelo mesmo programa. Bolsista CAPES. Advogada. É facilitadora e instrutora de cursos de Círculos de Construção de Paz certificada pelo TJPR e AJURIS. Coordenadora do GEJUR/UEPG. E-mail: palomagraf@hotmail.com
} 


\section{INTRODUÇÃO}

Atualmente, o movimento da justiça restaurativa tem vivenciado uma proliferação de práticas, acompanhada da diversificação nos âmbitos de sua aplicação nas searas institucionais. Apesar disso, segue vigorando nos estudos da área certa fluidez conceitual, permitindo a abrangência, sob um mesmo rótulo, de iniciativas bastantes distintas em seus objetivos. Ainda que essa abertura permita a flexibilidade nas formas de aplicação, há que se alertar para o risco de as indefinições mascararem o distanciamento da raiz abolicionista e a aproximação da justiça restaurativa do discurso jurídico liberal.

Se os estudos e práticas indicam que o "como" se revela bastante caro para a justiça restaurativa, a superação da racionalidade penal moderna demanda que os atores e estudiosos da área tampouco podem desconsiderar a importância do "para que" - uma clareza de objetivos especialmente relevante em tempos de proliferação do neoconservadorismo.

Diante desse cenário, a teoria marxista se mostra relevante para trazer sólido embasamento à consolidação de uma justiça restaurativa crítica. Em primeiro lugar, isso pode se dar através da reaproximação com a criminologia crítica de base marxista, ao denunciar as discrepâncias existentes entre o discurso liberal garantista e as práticas punitivas seletivas e estigmatizantes, operadas em prol dos interesses das classes dominantes. Além disso, a compreensão do fenômeno da luta de classes permite identificar alguns riscos à justiça restaurativa - tanto aqueles decorrentes do embate frontal causado pelo neoconservadorismo, quanto o mais sutil, ligado à cooptação liberal e ao consequente esvaziamento da perspectiva crítica e distanciamento do abolicionismo penal.

Em um ou em outro caso, os estudos empreendidos apontam para a importância do desenvolvimento de maior criticidade na práxis restaurativa, destacando, de forma mais intencional, seu caráter antipunitivista, bem como suas pretensões transformativas, em nível estrutural, contra os mecanismos interseccionais de opressão, não se restringindo à perspectiva individualista.

Diante disso, a provocação apresentada neste artigo, por meio de análise bibliográfica e abordagem dialética, tem como intuito refletir e provocar a criatividade para o enfrentamento da lógica punitivista que dê conta da abrangência das violências estruturais ao compreender a justiça restaurativa pela perspectiva crítica marxista.

\section{ENTRE O ABOLICIONISMO E O NEOPUNITIVISMO: NOÇÕES FLUIDAS DE JUSTIÇA RESTAURATIVA E SUAS VERTENTES}

Desde o início do processo de resgate de práticas tradicionais voltadas ao tratamento de situações envolvendo conflitos, danos e violências, as definições e, principalmente, os âmbitos de aplicação da justiça restaurativa têm passado por diversas modificações, a depender do contexto de incidência. Nesse sentido, Brancher (2017, p. 8) observa que, "Talhadas para o enfrentamento das mais dolorosas situações de crime e violência, as práticas restaurativas vão além, e se mostram úteis para produzir reflexões relevantes também quando estendidas à resolução de conflitos". Desta forma, a justiça restaurativa não se resume a uma técnica de resolução de conflito.

Essa versatilidade é verificada, no âmbito judicial ${ }^{1}$, pelo mapeamento de práticas restaurativas conduzidas pelo Conselho Nacional de Justiça (CNJ), segundo o qual as cortes brasileiras contam

\footnotetext{
'A opção por mencionar dados relativos a práticas judiciais decorre, unicamente, da falta de mapeamentos de abrangência nacional sobre as práticas restaurativas comunitárias. No entanto, importa ressaltar que o presente estudo não se pauta pela compreensão de que a justiça restaurativa necessite de qualquer tutela institucional. Nesse sentido, Fania Davis ressalta a visão de justiça restaurativa como movimento social, compreendida pela autora como "a loosely organized but sustained collective effort comprised of a range of individuals and groups seeking to transform social structures, institutions, and individual." (DAVIS, 2019, p. 35).
} 
com iniciativas de justiça restaurativa em diversas áreas, atendendo, para além dos casos criminais, situações ligadas à infância e adolescência (infracional, protetiva e escolar), ao direito das famílias, à violência doméstica, à prevenção de conflitos, às esferas cível e administrativa, dentre outras (CNJ, 2019).

Se, por um lado, essa diversificação no âmbito de aplicação das práticas restaurativas pode estar ligada ao aproveitamento de ferramentas úteis para a abordagem das mais variadas hipóteses conflitivas, também é possível perceber algum distanciamento das pretensões abolicionistas verificadas na origem da justiça restaurativa, quando sua maior preocupação era, efetivamente, se apresentar como uma alternativa ao punitivismo incrustado no discurso jurídico liberal (ACHUTTI, 2016). A verificação, ou não, de uma conformação com o Direito Penal moderno, varia de acordo com a noção de justiça restaurativa adotada pelas diversas vertentes, influenciadas pelos interesses de classes.

Não é à toa, aliás, que as tentativas de conceituação ainda se mostram inacabadas, revelando-se ilustrativas a abertura e as (in)definições apresentadas pelo Conselho Econômico e Social das Nações Unidas (ECOSOC), ao recomendar aos estados-membro a adoção de princípios básicos no uso de programas de justiça restaurativa em matéria criminal (Resolução no 2002/12):

1. "Programa de justiça restaurativa" significa qualquer programa que use processos restaurativos e busque obter resultados restaurativos.

2. "Processo restaurativo" significa qualquer processo onde a vítima e o infrator e, se apropriado, quaisquer outros indivíduos ou membros da comunidade afetados por um crime, participem conjunta e ativamente na resolução dos problemas decorrentes do crime, em geral com a ajuda de um facilitador. O processo restaurativo pode incluir a mediação, conciliação, e transação penal.

3. "Resultado restaurativo" significa um acordo obtido como resultado de um processo restaurativo. Resultados restaurativos incluem respostas e programas como reparação, restituição e serviço comunitário, visando atender necessidades individuais e coletivas e responsabilidades das partes e alcançar a reintegração da vítima e do infrator.

4. "Partes" significa a vítima, o infrator e quaisquer outros indivíduos ou membros da comunidade afetados pelo crime que possam estar envolvidos em um processo restaurativo. 5. "Facilitador" significa uma pessoa cujo papel é facilitar, de modo imparcial e justo, a participação das partes no processo restaurativo. (ONU, 2002).

No âmbito interno, o Conselho Nacional de Justiça, por meio da Resolução n 225/2016, fixou a Política Nacional de Justiça Restaurativa no âmbito do Poder Judiciário, trazendo, logo de início, o seguinte conceito:

Art. $1^{\circ}$. A Justiça Restaurativa constitui-se como um conjunto ordenado e sistêmico de princípios, métodos, técnicas e atividades próprias, que visa à conscientização sobre os fatores relacionais, institucionais e sociais motivadores de conflitos e violência, e por meio do qual os conflitos que geram dano, concreto ou abstrato, são solucionados de modo estruturado na seguinte forma:

I - é necessária a participação do ofensor, e, quando houver, da vítima, bem como, das suas famílias e dos demais envolvidos no fato danoso, com a presença dos representantes da comunidade direta ou indiretamente atingida pelo fato e de um ou mais facilitadores restaurativos;

II - as práticas restaurativas serão coordenadas por facilitadores restaurativos capacitados em técnicas autocompositivas e consensuais de solução de conflitos próprias da Justiça Restaurativa, podendo ser servidor do tribunal, agente público, voluntário ou indicado por entidades parceiras;

III - as práticas restaurativas terão como foco a satisfação das necessidades de todos os envolvidos, a responsabilização ativa daqueles que contribuíram direta ou indiretamente para a ocorrência do fato danoso e o empoderamento da comunidade, destacando a necessidade da reparação do dano e da recomposição do tecido social rompido pelo conflito e as suas implicações para o futuro. (CNJ, 2016). 
Seguindo a linha de tentar conciliar os movimentos de justiça restaurativa e o direito penal moderno, os excertos sugerem que, ao buscarem abranger iniciativas voltadas às mais variadas finalidades e pautadas por inúmeras (e por vezes antagônicas) orientações políticas, os Conselhos deixam de marcar um rompimento claro com o discurso jurídico oficial e com os interesses de classe por ele representados, deixando de lado as pretensões abolicionistas radicais.

A falta de precisão conceitual e finalística é ressaltada pela bibliografia internacional, demonstrando a complexidade da questão. Exemplificativamente, é de se destacar a sólida revisão bibliográfica trazida por Achutti (2016, p. 59-66) acerca da questão aberta em torno das diversas possibilidades de definição da justiça restaurativa, cuja leitura confirma que, tão grande quanto a fluidez conceitual, é a variedade de objetivos perscrutados por cada vertente que se assume como restaurativa.

Em outras palavras, as teorias que embasam a justiça restaurativa trazem consigo diversos conceitos, nem sempre compatíveis entre si. De acordo com Gade (2021), alguns estudiosos defendem que esta diferente forma de justiça pode ser compreendida como um processo (MARSHALL, 1999), enquanto outros a apresentam como uma teoria da justiça (VAN NESS, 2005). Há, ainda, quem adote o entendido segundo o qual se trata de uma intenção (WALGRAVE, 2012).

Buscando pontos de encontro apesar das divergências existentes entre as diversas concepções, à justiça restaurativa é atribuída a condição de "movimento social global" (VAN NESS, 2011, p. 5) com ampla e dinâmica diversidade de utilização e abordagens, que se ampliam para além de um encontro ou técnica.

No entendimento de Walgrave (2012, p. 11):

A justiça restaurativa é um produto inacabado. É um reino complexo e vivo de diferentes - e parcialmente opostas, crenças e opções, renovando inspirações e práticas em diferentes contextos, científicos "cruzando as espadas" sobre a metodologia e os resultados da pesquisa. A justiça restaurativa é, ao mesmo tempo, um movimento social com diferentes graus de autocrítica e um domínio de pesquisa científica com diferentes graus de adequação metodológica. É um campo próprio, à procura de maneiras construtivas de lidar com as consequências do crime, mas que também faz parte de uma agenda sócio-ética e política mais ampla.

Portanto, tem-se que a flexibilidade do entendimento acerca da justiça restaurativa pode ser uma potencialidade que permite compreendê-la como rompimento de estruturas, como um conjunto diverso, orgânico e vivo de ações, abordagens e princípios que se adequam aos movimentos históricos e territoriais, para dar conta de atender as necessidades locais e transformar as relações sociais, na medida do possível.

A essa altura, parece bastante nítido que, apesar das divergências sobre "o que" é, precisamente, a justiça restaurativa, o "como" se revela bastante caro para praticamente todas as vertentes, uma vez que se reconhece a necessidade de promover uma abordagem pautada pela ação coletiva e participativa dos envolvidos em uma situação de conflito, dano ou violência, incluindo vítimas, ofensores e comunidades (WACHTEL, 2016, p. 4).

Contudo, se neste movimento há a pretensão de superação da racionalidade penal moderna (COSTA; MACHADO JÚNIOR, 2018), é importante que os atores e estudiosos da área não se olvidem, também, da importância do "para que" da justiça restaurativa, enquanto abordagem sobre a justiça (compreendida como valor, não sob um aspecto institucional) contraposta ao sistema vigente e ao paradigma punitivista. Uma clareza de objetivos especialmente necessária em períodos marcados pelo 
neopunitivismo - quando se constatam a exacerbação da seletividade penal e a restrição dos direitos e garantias liberais a algumas classes sociais - e pelo avanço do neoconservadorismo pelo mundo.

Quer dizer, embora a fluidez conceitual e metodológica possa ensejar a vantagem de não engessamento das formas de aplicação, viabilizando a adaptação a cada caso e aos seus contextos culturais (ACHUTTI, 2016), é possível que algumas indefinições mascarem os interesses contrapostos, sustentados por diversas vertentes, sob o mesmo rótulo restaurativo. Segundo Koen (2005), esse cenário é agravado pela falta de criticidade nos estudos - não obstante a profusão literária sobre a temática da justiça restaurativa nos últimos anos.

Diante do quadro delineado, a proposta aqui defendida é que a teoria marxista pode trazer elementos relevantes do "para que" das práticas restaurativas, no intuito de que sejam empregadas de forma crítica, com sólido embasamento para se contrapor ao discurso jurídico-penal moderno e buscando o enfrentamento das violências estruturais que ensejam transformações sociais mais profundas do que a resolução de conflitos individuais.

\section{APROXIMAÇÕES POSSÍVEIS ENTRE A JUSTIÇA RESTAURATIVA (CRÍTICA) E A CRIMINOLOGIA MARXISTA}

A relevância do pensamento marxista para o desenvolvimento de uma vertente crítica e abolicionista da justiça restaurativa pode ser percebida, inicialmente, por meio da relativa consonância entre as primeiras críticas do movimento restaurativista ao paradigma punitivista e as análises da criminologia crítica marxista (KOEN, 2005; ACHUTTI, 2016; DAVIS; 2020), denunciando as inconsistências entre o discurso liberal garantista e as práticas punitivas seletivas e estigmatizantes, movidas pelos interesses das classes dominantes.

Nessa linha, Juarez Cirino dos Santos se apoia no materialismo histórico marxista para identificar os "objetivos reais do discurso jurídico crítico" (SANTOS, 2006, p. 6), em contraposição àquilo que chama de "objetivos declarados do discurso jurídico oficial" (SANTOS, 2006, p. 4). Se nestes o liberalismo afirma o direito penal como a ultima ratio, responsável pela proteção de bens jurídicos, aqueles escancaram o controle social seletivo, marcado pela luta de classes.

Inclusive, é na luta de classes, desenhada conforme o modo de produção vigente, que Santos encontra o ponto de partida para infirmar a aparência de neutralidade do direito penal. Em resumo:

O conceito de modo de produção desenvolvido pelo pensamento marxista, formado pela articulação de forças produtivas em determinadas relações de produção da vida material, permite identificar os objetivos reais do Direito, em geral - cuja existência é encoberta pelos objetivos declarados do discurso jurídico oficial -, que revelam o significado político do Direito Penal como instituição de garantia e de reprodução da estrutura de classes da sociedade, da desigualdade entre as classes sociais, da exploração e da opressão das classes sociais subalternas pelas classes sociais hegemônicas nas sociedades contemporâneas. (SANTOS, 2006, p. 8).

A verificação de que a lei penal encontra seu fundamento real nos "interesses, necessidades e valores das classes sociais dominantes das relações de produção e hegemônicas do poder político do Estado, como indicam as teorias conflituais da Sociologia do Direito" (SANTOS, 2006, p. 7) se fundamenta na leitura de Marx acerca da forma como, dentro da luta de classes, o Estado moderno e o direito não atuam de maneira neutra, mas representam os interesses da burguesia: 
Vossas próprias ideias são produto das relações de produção e de propriedade burguesas, assim como vosso direito não passa da vontade de vossa classe erigida em lei, vontade cujo conteúdo é determinado pelas condições materiais de vossa existência como classe.

Essa concepção interesseira, que vos leva a transformar em leis eternas da natureza e da razão as relações sociais oriundas do vosso modo de produção e de propriedade. (MARX; ENGELS, 2010, p. 55-56).

Partindo da crítica marxista ao direito como "forma social própria do capitalismo" (PAZELLO; SOARES, 2014, p. 484), a criminologia crítica percebe, entre o direito penal nas sociedades capitalistas e os interesses de classe (ou entre cárcere e fábrica), uma relação de causa e consequência em mão dupla, com os mecanismos repressivos oficiais ora reproduzindo, ora promovendo a discriminação social, sempre em prol da conservação e reprodução dos mecanismos de exclusão e opressão (BARATTA, 2011).

Sobre as formas como esses processos de neutralização das classes indesejadas ocorrem na aplicação do direito penal moderno, Baratta explicita, através dos conceitos de criminalização primária e de criminalização secundária:

No que se refere ao direito penal abstrato (isto é, à criminalização primária), isto tem a ver com os conteúdos, mas também com os "não conteúdos" da lei penal. O sistema de valores que neles se exprime reflete, predominantemente, o universo moral próprio de uma cultura burguesa-individualista, dando a máxima ênfase à proteção do patrimônio privado e orientando-se, predominantemente, para atingir as formas de desvio típicas dos grupos socialmente mais débeis e marginalizados. Basta pensar na enorme incidência de delitos contra o patrimônio na massa da criminalidade [...], a preservar da criminalização primária as ações antissociais realizadas por integrantes das classes sociais hegemônicas, ou que são mais funcionais às exigências do processo de acumulação do capital. Criam-se, assim, zonas de imunização para comportamentos cuja danosidade se volta particularmente contra as classes subalternas.

Os processos de criminalização secundária acentuam o caráter seletivo do sistema penal abstrato. Têm sido estudados os preconceitos e os estereótipos que guiam a ação tanto dos órgãos investigadores como dos órgãos judicantes, e que os levam, portanto, [...] a procurar a verdadeira criminalidade principalmente naqueles estratos sociais dos quais é normal esperá-la. (BARATTA, 2011, p. 176).

Ao identificar tais segmentos da sociedade nos quais os mecanismos de criminalização secundária procuram os desvios de forma mais intensa, a criminologia crítica parte do pensamento marxista sobre as manifestações da luta de classes no direito e a expande, propondo uma perspectiva transformadora ampla, que ataque os contextos opressivos em geral, de acordo com a teoria da interseccionalidade - semelhantemente ao que ocorre em algumas linhas dos feminismos marxistas (ARRUZZA, 2010).

Mais especificamente na perspectiva abolicionista, Angela Davis também toma os interesses de classe como ponto de partida para identificar as políticas de encarceramento em massa como um projeto político a serviço das elites econômicas, ao qual se sucedem outras formas de opressão, como as de raça ${ }^{2}$ e de gênero:

\footnotetext{
${ }^{2}$ Sobre o uso da prisão como forma de perpetuação da ordem racial, destaca-se: "A sobrerrepresentação maciça e crescente dos negros em todos os patamares do aparelho penal esclarece perfeitamente a segunda função assumida pelo sistema carcerário no novo governo da miséria nos Estados Unidos: substituir o gueto como instrumento de encerramento de uma população considerada tanto desviante e perigosa como supérflua, no plano econômico [...] assim como no político [...]. Nesse aspecto, a prisão é apenas a manifestação paroxística da lógica de exclusão da qual o gueto é o instrumento e o produto desde sua origem histórica [...]." (WACQUANT, 2011, p. 105-106).
} 
Teríamos que reconhecer que o "castigo" não é uma consequência do "crime" na sequência lógica e simples oferecida pelos discursos que insistem na justiça do aprisionamento, mas sim que a punição - principalmente por meio do encarceramento (e às vezes da morte) - está vinculada a projetos de políticos, ao desejo de lucro das corporações e às representações midiáticas do crime. O encarceramento está associado à racialização daqueles que têm mais probabilidade de ser punidos. Está associado a sua classe e, como vimos, a seu gênero, que também estrutura o sistema penal. Se insistimos que as alternativas abolicionistas perturbam essas relações, que se esforçam para desvincular crime e punição, raça e punição, classe e punição, gênero e punição, então nosso foco não pode se restringir apenas ao sistema prisional como uma instituição isolada, mas deve se voltar também para todas as relações sociais que sustentam a permanência da prisão. (DAVIS, 2020, p. 121).

O alerta trazido por Angela Davis ao movimento abolicionista serve, também, para o movimento da justiça restaurativa, identificado pela mesma autora como uma - dentre várias - alternativas abolicionistas possíveis (DAVIS, 2020).

Ter em mente que o sistema penal moderno corresponde aos interesses de uma determinada classe, e se relaciona com contextos interseccionais de opressão, é importante para evitar que os promotores da justiça restaurativa assumam um papel de naturalização e legitimação do sistema de justiça posto e do próprio discurso jurídico moderno. Em outras palavras, trata-se de não se contentar com o papel coadjuvante na cena liberal, que aceita - e promove - o rótulo da justiça restaurativa, desde que esta se restrinja a uma via alternativa, acrítica ao modo de funcionamento das instituições penais e à utilização do cárcere como instrumento de dominação de classe, de raça e de gênero.

Dessa forma, não basta utilizar práticas restaurativas sem qualquer contraposição à lógica punitivista neoliberal, revelando-se ser necessário o desenvolvimento de uma justiça restaurativa crítica, que reconheça expressamente a falência do sistema carcerário, e se apresente como uma das alternativas possíveis ao colapso do discurso liberal das teorias da pena (COSTA; MACHADO JÚNIOR, 2018).

Assim, a justiça restaurativa apresenta um potencial emancipatório e subversivo, pois as narrativas são trocadas e o protagonismo das populações historicamente marginalizadas pelo Estado e pela sociedade são reconhecidos. No entanto, é preciso escutar essas vozes e atribuir poder para a tomada de decisão sobre o encaminhamento dos conflitos sociais dos quais são parte, pois o potencial transformativo da justiça restaurativa somente será alcançado quando houver responsabilização e reciprocidade do Estado por parte dos danos causados à sua população.

As aspirações de justiça restaurativa transcendem a questão da criminalidade, pois, a maioria dos restaurativistas não a consideram somente como um projeto de combate ao crime, mas também, como forma de antecipar o atendimento das relações anteriores, expandido sua capacidade e resiliências para o enfrentamento, e até mesmo como capaz de erradicar as fontes causadoras da criminalidade - isto é pode ser considerada como uma potencial e radical fonte de transformação e mudança no que diz respeito à existência para os envolvidos (KOEN, 2005). Assim, é preciso repensar a radicalidade restaurativa, pois:

A justiça restaurativa, concebida como uma tradição intelectual ou como uma abordagem da prática política, envolve uma transformação radical. Sobre isso, a visão radical da justiça restaurativa não é simplesmente uma forma de reformar o sistema de justiça criminal, é uma forma de transformar todo o sistema jurídico, nossa vida familiar, nossa conduta no local de trabalho, nossa prática de política. Sua visão é de uma mudança holística na forma como fazemos justiça no mundo. (BRAITHWAITE, 2003, p. 1 apud KOEN, 2005) 
A radicalidade, por conseguinte, reside na ideia de um novo jeito de fazer justiça e existirmos uns com os outros (KOEN, 2005). Quando se fala em uma justiça restaurativa pautada pela perspectiva crítica, destaca-se um primeiro aspecto de resgate da práxis de povos tradicionais e marginalizados (ORTH; GRAF, 2020), guardando estreita relação com a valorização de epistemologias periféricas potencialmente emancipatórias. Um reconhecimento epistemológico que permite falar, por exemplo, em "sulear a justiça restaurativa"3 (ORTH; BOURGUIGNON; GRAF, 2020).

Neste ponto, oportuno destacar as críticas de Boonen (2020), quanto às lacunas existentes na segunda edição do manual "Handbook on Restorative Justice Programmes" (UNODC, 2020) quanto às necessárias reflexões sobre a justiça restaurativa e o contexto de desigualdade social. Boonen (2020) descreve sobre o compromisso que a justiça restaurativa deve ter com o desencarceramento, pois, conforme aponta, são os homens jovens, negros, pobres e com baixa escolaridade que permanecem privados de liberdade nas prisões superlotadas, mormente no contexto brasileiro. Como a justiça restaurativa se apresenta como uma solução para alguns, ela corre grande risco de ser cooptada pela lógica funcional racional do sistema de justiça criminal, que exclui os envolvidos do gerenciamento de seus próprios conflitos ao esquecer de suas origens fundantes, como a criminologia crítica e o abolicionismo penal. Isso porque, ao deixar de questionar as discrepâncias sociais que podem provocar a construção de políticas públicas que atendam às necessidades e as mazelas enfrentadas pela sua população, como por exemplo, o encarceramento em massa, a exclusão social e a criminalização da pobreza, a justiça restaurativa se distancia da sua essência.

Posto isso, é preciso reconhecer as violências estruturais a que estamos submetidos em cada território, pois muitas delas derivam de outras que estimulam o viés autoritário e punitivista do judiciário para a solução/transformação de conflitos sociais. Desta forma, "enquanto o movimento pela justiça restaurativa limitar seu foco aos danos feitos por indivíduos hoje, o trabalho se mostrará superficial e sem efeito" (VALANDRA, HOKSÍLA, 2020, p. 323), tendo em vista que é crucial reconhecer e responsabilizar os causadores de danos causados sofridos pela população, diante das violências estruturais perpetradas pelo Estado.

Além da valorização dos saberes não dominantes, a justiça restaurativa crítica se apoia em uma concepção que não se quer restringir a um método de resolução de conflitos individuais, nem se pretende limitar a um aditivo às abordagens punitivas tradicionais (ACHUTTI, 2016; DAVIS, 2020), mas que proponha transformações estruturais, inclusive dos contextos sociais corresponsáveis pela ocorrência das situações de dano, violência ou conflito.

Ao refletir sobre esses contextos marcados pelas opressões interseccionais, Fania Davis (2019) identifica possibilidades de integração entre diversos movimentos sociais (como os antirracistas, abolicionistas e feministas) e a justiça restaurativa - esta também considerada como um movimento social. A autora ressalta, então, que a justiça restaurativa não deve buscar, apenas, uma forma mais adequada de fazer justiça no caso concreto; antes, precisa adotar uma visão mais ampla, rumo à

\footnotetext{
${ }^{3}$ Sulear a justiça restaurativa significa ultrapassar os maniqueísmos, principalmente os geográficos, e construir diferentes conceitos e abordagens restaurativas enraizadas nas nossas próprias circunstâncias que refletem a complexa realidade que temos e vivemos a partir do próprio território. Sulear faz parte do movimento questionador do que é justiça? Justiça de quem? Para quem? Como os sujeitos experimentam segurança e reparação de dano de formas diferentes, face às suas diversas e complexas narrativas a partir dos seus contextos históricos, é necessário compreender de onde falam, para distinguir e entender como tais signos reverberam nestes sujeitos os diferentes significados de justiça, levando em consideração sua condição social, econômica, geográfica e cultural, além dos atravessamentos de classe, raça e gênero (ORTH; BOURGUIGNON; GRAF, 2020).
} 
JUSTIÇA RESTAURATIVA, CRIMINOLOGIA CRÍTICA E COOPTAÇÃO LIBERAL: POSSÍVEIS CONTRIBUTOS DA TEORIA MARXISTA A UMA JUSTIÇA...

transformação das estruturas sociais e das instituições causadoras de danos massivos, sob pena de oferecer soluções rápidas aos sintomas, mas não às causas subjacentes aos danos ${ }^{4}$ (DAVIS, 2019).

Em suma, como nas palavras de Achutti, trata-se de firmar que, em sua vertente crítica e abolicionista, a justiça restaurativa

[...]não pode virar uma presa do sistema penal, para evitar que seja relegada ao papel de mero suplemento expansionista do poder punitivo; [e] exige a adoção de uma nova linguagem para o seu funcionamento, para que não seja colonizada pelas práticas e pelas noções tradicionais da justiça criminal; (ACHUTTI, 2016, p. 125)

Afora a oferta de sólidos fundamentos para identificar a necessidade de desenvolvimento de uma justiça restaurativa crítica, o pensamento marxista também se mostra relevante para apontar como, sem essa perspectiva crítica, o movimento da justiça restaurativa, na dinâmica da luta de classes, pode acabar se tornando irrelevante do ponto de vista do combate ao paradigma punitivista.

\section{DA REAÇÃO NEOCONSERVADORA À COOPTAÇÃO LIBERAL: RISCOS AO MOVIMENTO DA JUSTIÇA RESTAURATIVA IDENTIFICADOS A PARTIR DA LUTA DE CLASSES}

Em O 18 de Brumário de Luís Bonaparte (MARX, 2011), Marx demonstra como o conhecimento da história pela perspectiva dialética, com a compreensão de como a luta de classes se opera na prática, é essencial para uma leitura mais precisa sobre os contextos sócio-políticos, ao desmascarar as pretensões de dominação vigentes. E se "a história de todas as sociedades até hoje existentes é a história da luta de classes" (MARX; ENGELS, 2010, p. 40), é de se esperar que os movimentos ligados à crítica do direito, em geral, também sejam por ela diretamente impactados.

A esse respeito, Pazello e Soares apontam como o "processo de falência da crítica" conduz aos "escombros das teorias críticas do direito" (PAZELLO; SOARES, 2014, p. 476), tomando como objeto de análise os movimentos brasileiros do direito alternativo e do pluralismo jurídico. Uma história que deve servir de alerta, também, ao movimento da justiça restaurativa.

Conforme ressaltado no tópico anterior, o distanciamento da criminologia marxista e a falta de compromisso claro com uma perspectiva crítica abolicionista tendem a esvaziar a justiça restaurativa, retirando-lhe, justamente, seu aspecto radical de contraposição ao paradigma punitivista, e relegando-a a um papel de acessório dos mecanismos de controle social. Risco esse que não se resume a uma mera possibilidade aleatória, mas se relaciona, dentro da lógica da luta de classes, com uma estratégia de reação (neo)liberal ao potencial efetivamente transformador da justiça restaurativa, enquanto movimento social com pretensões de questionamento e ruptura com algumas das bases do sistema jurídico moderno em geral e, especificamente, da lógica do encarceramento.

Em um primeiro nível mais evidente de reação, a justiça restaurativa é identificada e combatida diretamente pelos segmentos neoconservadores, os quais, desde o final do século XX (sobretudo no cenário estadunidense) e especialmente a partir da segunda década do século XXI (em movimento internacional, inclusive no Brasil ${ }^{5}$ ), passam, deliberadamente, a causar a quebra de pressupostos

\footnotetext{
${ }^{4}$ Aqui, Fania Davis lança mão de uma analogia, para explicar que a justiça restaurativa que não busca compreender e transformar os contextos de opressão corresponsáveis pelo dano é semelhante ao jardineiro que, preocupado com o bemestar individual de suas plantas, ignora a importância de um solo saudável. Desta forma, é difícil não relacionar a metáfora com a ideia marxista de infra e superestrutura, a qual reforça os interesses únicos da classe dominante.

${ }^{5}$ Sobre o neoconservadorismo brasileiro, destaca-se: "A configuração da desnaturação constitucional no país se verifica desde a abertura do procedimento de impeachment em 2016, passando por alterações desconstituintes neoliberais de enxugamento dos gastos públicos e de retirada de direitos constitucionalmente assegurados. Este processo é marcado pelo neoconservadorismo político, fenômeno que opera a partir de um binômio de conservadorismo moral e neoliberalismo
} 
democráticos e sociais, atuando de mãos dadas com o neoliberalismo na defesa dos interesses econômicos das classes hegemônicas (KREUZ, 2020). Nessa linha, algumas das mais marcantes pautas dos "novos" conservadores estão, justamente, atreladas ao punitivismo exacerbado, como a redução da maioridade penal, a extirpação de garantias processuais (leia-se, aos inimigos), o aumento e agravamento de penas, a guerra às drogas e o incentivo ao encarceramento em massa. Logo, é possível que movimentos pautados na alteridade dialógica e crítico às violações decorrentes da aplicação do direito penal, como a justiça restaurativa, sejam encarados e atacados como ameaças.

Contudo, um risco mais sutil é, não o de combate direto, mas o de esvaziamento da justiça restaurativa - ao menos em sua concepção mais radical de transformação de todas as relações, conforme apontado por Koen (2005). Trata-se da possibilidade de enfraquecimento interno, semelhante ao já mencionado processo referido por Pazello e Soares (2014) quanto aos outros movimentos críticos do direito, retirando-lhe a matriz crítica abolicionista. Quer dizer, ainda que se mantenha o rótulo bem-conceituado da justiça restaurativa, pode-se esvaziar sua proposta estruturalmente abolicionista e emancipatória, de transformação dos contextos sociais subjacentes às situações de violência, dano ou conflito ao relegá-la a mero método ou técnica de resolução de litígios.

Trata-se, em outras palavras, de uma cooptação levada a cabo por atores da racionalidade liberal, dispostos a utilizar e a incentivar o uso preciso de práticas restaurativas, mas reduzindo-as à categoria de método e restringindo - quando não excluindo completamente - sua abordagem potencialmente transformadora aos aspectos individualistas. Sobre tal cooptação liberal, merece destaque:

Um dos riscos centrais desse tipo de abertura é justamente sua cooptação pela epistemologia neoliberal que, no anseio pelo reforço do individualismo, pela desresponsabilização e enfraquecimento da instância estatal e pela gestão do Poder Judiciário em termos de custos e benefícios, maximizando o anseio por celeridade, acaba por produzir modalidades de censura diametralmente opostos à sua fundação na alteridade e na responsabilidade, "liberando" o discurso punitivo de quaisquer limites e intensificando sua aflitividade.

É evidente que assim não pode ser e que não deve ser tomada a sério qualquer proposta de institucionalização de práticas restaurativas que signifique a sua cooptação pelo sistema penal, descaracterizando-as como limite ao discurso punitivo. Não se opõe, porém, à possibilidade estratégica de sua convivência em paralelo, apostando na gradual e inevitável deslegitimação do sistema punitivo decorrente da compreensão, por todos, de que práticas de censura sem punir e sem destruir o outro são possíveis. (GIAMBERARDINO, 2015, p. 231).

Apesar da validade desse uso estratégico apontado por Giamberardino, de convivência da justiça restaurativa crítica com o uso das práticas restaurativas segundo a lógica individualista, importa pontuar que, tanto o ataque ostensivo e deliberado à justiça restaurativa, como a sua limitação a um método consensual de resolução de conflitos individuais, paralelo ao sistema de justiça estatal, atendem aos interesses de classe específicos.

Afinal, conforme reiteradamente denunciado pela criminologia marxista, todas as estratégias de manutenção da seletividade penal e do encarceramento em massa interessam às elites econômicas, que se beneficiam do encarceramento em massa de pessoas pretas e pobres (FÓRUM BRASILEIRO DE SEGURANÇA PÚBLICA, 2020), e que alimenta uma guerra às drogas há muito fracassada em seus objetivos declarados, priorizando a proteção do patrimônio sobre a democracia e os direitos humanos.

econômico, com a expectativa de "retorno" dos ideais morais da família tradicional brasileira, um patriotismo ufanista e apoiado na bandeira do combate à corrupção. Dessa forma, aliado aos setores tradicionais da direita brasileira - sempre fortemente presentes na Nova República -, o novo conservadorismo brasileiro abriu as portas para a desnaturação da Constituição." (KREUZ, 2020, p.2650). 
Segundo Findlay (2000, apud CLAMP, 2019), a justiça restaurativa, por vezes, falha ao desrespeitar as linhas guias do modelo que promove, bem como em enfrentar as tensões em relação aos sistemas que pretende substituir. Portanto, para que não haja "uma nova onda de colonialismo no domínio atual do controle social" (CLAMP, 2019, p. 458) na utilização e disseminação da justiça restaurativa, se faz necessário romper com o ideal de prescrição única e universal de práticas restaurativas (CLAMP, 2019) para que seja possível criar diferentes estratégias que cuidem das necessidades locais e oportunizem o desenvolvimento de processos relevantes do ponto de vista cultural e social.

Por tudo isso, qualquer tentativa reducionista de substituir o paradigma punitivista sem ter em mente essas realidades complexas, marcadas pela luta de classes, corre o risco de perder seu componente crítico e, por conseguinte, sua relevância enquanto movimento potencialmente emancipatório e coletivo. No caso da justiça restaurativa, conforme já mencionado, o risco concreto é o de multiplicação de abordagens restaurativas que retiram o abolicionismo penal de suas bases axiológicas, reduzindo-as a vias paralelas ao sistema penal oficial e voltadas, exclusivamente, à abordagem de casos individuais através de técnicas judiciais de resolução de conflitos.

Neste sentido, defende Koen (2005) que a análise da justiça restaurativa deve ser aliada à teoria marxista, pois a reivindicações desta diferente forma de fazer justiça devem considerar as noções de classe e luta de classes:

[...] os defensores da justiça restaurativa parecem ter pouca consideração pelo efeito que estas noções podem ter sobre seu projeto, sua implementação e o tipo de justiça que entrega. O impacto da classe social é extenso e profundo, e pouquíssimos profissionais da justiça criminal hoje em dia tentariam negar ou ignorar a relação entre classe e criminalidade. No entanto, os restaurativistas argumentam rotineiramente e promovem seu projeto como se a sociedade em que vivemos ou a comunidade em que eles operam não tivesse classe, pelo menos no sentido de que não é afetado por conflito de classes. Isto obviamente é inaceitável, mesmo de uma perspectiva sociológica não marxista. O peso da classe social é simplesmente grande demais para contornar completamente e deve ser levado em conta em qualquer análise séria da justiça restaurativa.(2005, p. 24)

É preciso ter em mente, então, que as estratégias de reação são relevantes, especialmente, nos cenários neoliberais, nos quais o individualismo e a busca pela punição do outro a qualquer custo se revelam mais exacerbadas. Se o capitalismo promove a reificação do outro e o direito burguês reflete essa mercantilização das relações (PACHUKANIS, 2017), a perspectiva crítica sobre o direito não pode ser ignorada por um movimento que pretenda, em sua práxis, resgatar a humanização dos vínculos relacionais, buscando a responsabilização pelo dano com base na alteridade e evitando "conscientemente os mecanismos de desumanização recíproca entre responsável ou acusado pelo ato e os sujeitos vitimizados" (GIAMBERARDINO, 2015, p. 136).

Dessa forma, ainda que haja certas áreas de tensão (ou mesmo incompatibilidades) entre alguns dos valores e objetivos restaurativos e a teoria marxista (como criticado por KOEN, 2005), é certo que, em se tratando de um movimento voltado à transformação de contextos sociais prejudicados pelos mecanismos de opressão, e que se propõe como alternativa viável à racionalidade penal burguesa, o pensamento marxista pode, sim, oferecer contribuições relevantes para o desenvolvimento de uma vertente crítica e abolicionista da justiça restaurativa. 


\section{CONCLUSÃO}

A justiça restaurativa pode ser uma potencial solução para a crise da criminalidade ao romper com a lógica da racionalidade penal moderna e burguesa e apresentar algo diferente de tudo que foi proposto anteriormente. As reivindicações transformativas da justiça restaurativa permitem o gerenciamento de abordagens, técnicas e métodos diferenciados que proporcionem o enfrentamento indispensável para o atendimento de uma justiça emancipatória e radical.

No entanto, a falta de perspectiva crítica ao movimento da justiça restaurativa pode ensejar o esvaziamento de seu potencial transformador, relegando-a, quando muito, ao papel de mero método consensual de resolução de conflitos, sem maiores pretensões de transformação social/coletiva e de contraposição ao punitivismo liberal e ao discurso jurídico moderno em geral.

Embora a disseminação da justiça restaurativa e sua abertura conceitual tenha aspectos positivos e revolucionários, importante ter em mente que seguir o mesmo rumo do sistema de justiça moderno, apenas se colocando como uma via paralela coexistente ao direito penal, equivale a legitimar velhas práticas punitivas, conferindo-lhes roupagem restaurativa.

Enxergar as distintas vertentes dentro do movimento da justiça restaurativa e compreender como essas variações se relacionam com a luta de classes é fundamental para obter uma maior clareza acerca dos fins pretendidos e encontrar o "para que" transformativo da justiça restaurativa.

Nessa toada, verifica-se que uma justiça restaurativa crítica, voltada à transformação estrutural dos contextos nos quais as situações de conflito, dano e violência ocorrem, e intencionalmente contraposta ao paradigma punitivista, ganha muito mais capacidade de apreensão da realidade a partir das contribuições da teoria marxista. Afinal, é a representação dos interesses das classes dominantes nas instituições de controle social formal que tem o poder de cooptar a justiça restaurativa, apreender seu discurso e sua técnica e esvaziá-la de seu conteúdo estruturalmente transformador, distanciando-a das origens ligadas ao abolicionismo e à criminologia crítica.

Ainda que entre o marxismo e a justiça restaurativa subsistam espaços de tensão, a teoria marxista pode oferecer contributos relevantes para o desenvolvimento de uma justiça restaurativa crítica e emancipatória; seja por meio do resgate das críticas da criminologia marxista ao direito penal moderno, seja por meio da percepção sobre como a luta de classes influencia os movimentos reacionários contra a consolidação da perspectiva crítica dentro do movimento restaurativo.

\section{REFERÊNCIAS}

ACHUTTI, Daniel. Justiça Restaurativa e Abolicionismo Penal: contribuições para um novo modelo de administração de conflitos no Brasil. 2. ed. São Paulo: Saraiva, 2016.

ARRUZZA, Cinzia. Feminismo e marxismo: entre casamentos e divórcios. Lisboa: Edições Combate, 2010.

BARATTA, Alessandro. Criminologia crítica e crítica do Direito Penal: introdução à sociologia do direito penal. 6. ed. Rio de Janeiro: Revan, 2011.

BOONEN, Petronella Maria. Sulear a justiça restaurativa é ampliar suas abordagens. In: ORTH, Glaucia Mayara Niedermeyer; GRAF, Paloma Machado (Org.). Sulear a justiça restaurativa: as contribuições latino-americanas para a construção do movimento restaurativo. Ponta Grossa: Texto e Contexto, 2020 (Coleção Singularis, V.8), p. 37-53. 
JUSTIÇA RESTAURATIVA, CRIMINOLOGIA CRÍTICA E COOPTAÇÃO LIBERAL: POSSÍVEIS CONTRIBUTOS DA TEORIA MARXISTA A UMA JUSTIÇA...

BRANCHER, Leoberto. Prefácio. In: ZEHR, Howard. Justiça Restaurativa. 2. ed. São Paulo: Palas Athena, 2017.

CLAMP, Kerry. Transforming Restorative Justice for Transitional Settings. 2019.

CONSELHO NACIONAL DE JUSTIÇA (CNJ). Resolução $\mathbf{n}^{\circ}$ 225. Dispõe sobre a Política Nacional de Justiça Restaurativa no âmbito do Poder Judiciário e dá outras providências. Brasília, 31 de maio de 2016. Disponível em: https://atos.cnj.jus.br/atos/detalhar/2289. Acesso em 17 out 2020.

CONSELHO NACIONAL DE JUSTIÇA (CNJ). Seminário Justiça Restaurativa: mapeamento dos programas de justiça restaurativa. Brasília: CNJ, 2019. Disponível em: http://www.cnj.jus.br/files/ conteudo/arquivo/2019/06/8e6cf55c06c5593974bfb8803a8697f3.pdf. Acesso em: 02 jun. 2021.

COSTA, Daniela Carvalho Almeida da; MACHADO JÚNIOR, Elisio Augusto de Souza. Justiça Restaurativa: um caminho possível na superação da racionalidade penal moderna? Revista da Faculdade de Direito UFPR, Curitiba, PR, Brasil, v. 63, n. 1, p. 65-91, abr. 2018. Disponível em http:// revistas.ufpr.br/direito/article/view/54226. Acesso em: 30 abr. 2018.

DAVIS, Angela. Estarão as prisões obsoletas?. 7 ed. Rio de Janeiro: Difel, 2020.

DAVIS, Fania. The little book of race and restorative justice: black lives, healing and US social transformation. Nova lorque: Good Books, 2019.

FÓRUM BRASILEIRO DE SEGURANÇA PÚBLICA (FBSP). Anuário brasileiro de segurança pública 2020. 2020. Disponível em: https://forumseguranca.org.br/wp-content/uploads/2020/10/anuario-14-2020v1-interativo.pdf. Acesso em: 22 out. 2020.

GADE, Christian BN. Is restorative justice punishment? Conflict Resolution Quarterly. 2021;38:127-155.

GIAMBERARDINO, André. Crítica da pena e justiça restaurativa: a censura para além da punição. Florianópolis: Empório do direito, 2015.

KOEN, Raymond Anthony. Restorative justice: a marxist analysis. 2005. Tese (Doctor of Philosophy in the institute of criminology), University of Cape Town, Cidade do Cabo, 2005.

KREUZ, Letícia Regina Camargo. Constitucionalismo nos tempos do cólera: neoconservadorismo e desnaturação constitucional. 2020. Tese (Doutorado em Direito), Universidade Federal do Paraná, Curitiba, 2020.

MARSHALL, Tony. Restorative justice: An overview. London: Home Office Research Development and Statistics Directorate. 1999.

MARX, Karl; ENGELS, Friedrich. Manifesto comunista. 1. ed. rev. São Paulo: Boitempo, 2010.

MARX, Karl. O 18 Brumário de Luís Bonaparte. São Paulo: Boitempo, 2011.

ORGANIZAÇÃO DAS NAÇÕES UNIDAS (ONU). Conselho Econômico e Social. Resolução n 2002/12. Princípios básicos do uso de programas de justiça restaurativa em questões criminais. 24 de Julho de 2002. Disponível em: https://www.unodc.org/documents/justice-and-prison-reform/projects/ UN_Standards_and_Norms_CPCJ_-_Portuguesel.pdf. Acesso em: 17 out. 2020.

ORTH, Glaucia Mayara Niedermeyer; BOURGUIGNON, Jussara Ayres; GRAF, Paloma Machado. O sul também existe: intersecção entre o pensamento suleador e as práticas restaurativas no Brasil, in Sulear a justiça restaurativa: as contribuições latino-americanas para a construção do movimento restaurativo. Glaucia Mayara Niedermeyer; GRAF, Paloma Machado (Org.). Ponta Grossa: Texto e Contexto, 2020 (Coleção Singularis, V.8) 
PACHUKANIS, Evguieni. Teoria geral do direito e marxismo. São Paulo: Boitempo, 2017.

PAZELLO, Ricardo; SOARES, Moisés Alves. Direito e marxismo: entre o antinormativo e o insurgente Revista Direito e Práxis, [S.I.], v. 5, n. 2, p. 475-500, dez. 2014. ISSN 2179-8966. Disponível em: https:// www.epublicacoes.verj.br/index.php/revistaceaju/article/view/13109. Acesso em: 04 jun. 2021.

SANTOS, Juarez Cirino dos. Direito penal: parte geral. Curitiba: ICPC; Lumen Juris, 2006.

UNODC. Handbook on restorative justice programmes. Vienna: United Nations. 2020. Disponível em: https://www.unodc.org/documents/justice-and-prison-reform/20-01146_Handbook_on_Restorative_ Justice_Programmes.pdf.Acesso em 10/09/2020

VALANDRA, Edward C., HOKSÍLA, Undoing The First Harm: Settlers in Restorative Justice. In: Colorizing restorative justice: voicing our realities. (Org.) Edward C Valandra. Editora: Living Justice Press. 2020.

VAN NESS, D. W. An overview of restorative justice around the world. In Eleventh United Nations congress on crime prevention and criminal justice. Vancouver: International Centre for Criminal Law Reform and Criminal Justice Policy. 2005.

WACHTEL, Ted. Defining restorative. IIRP Graduate School, online, nov. 2016. Disponível em: https:// www.iirp.edu/images/pdf/Defining-Restorative_Nov-2016.pdf. Acesso em: 21 abr. 2021.

WACQUANT, Loïc. As prisões da miséria. 2. ed. Rio de Janeiro: Zahar, 2011.

WALGRAVE, Lode. Restorative justice, self-interest and responsible citzenship. Nova lorque:Routledge, 2012. 